\title{
A PRELIMINARY LOOK AT THE STRUCTURAL DIFFERENCES OF HIGHER EDUCATION CLASSROOM COMMUNITIES IN TRADITIONAL AND ALN COURSES
}

\section{A. Alfred P. Rovai, Ph.D.}

School of Education, Regent University

1000 Regent University Drive

Virginia Beach, Virginia 23464-9800

Phone: (757) 226-4861

Fax: (757) 226-4147

E-mail: alfrrov@regent.edu

\begin{abstract}
This preliminary study again provides evidence that it is the method and not the media that matters the most in learning effectiveness. The present work examines classroom community in order to determine how sense of community differs between students enrolled in traditional face-to-face and those enrolled in asynchronous learning network (ALN) courses. Subjects consist of 326 adult learners who were enrolled in a mix of 14 undergraduate and graduate courses at two urban universities. As operationalized by the Sense of Classroom Community Index (SCCI), there appears no significant difference in classroom community between the two groups of subjects. However, a discriminant analysis shows a significant overall difference in community structure between the two groups. Variations between groups on feelings of similarity of needs, recognition, importance of learning, connectedness, friendship, thinking critically, safety, acceptance, group identity, and absence of confusion are the characteristics contributing mostly to this difference in learning effectiveness.
\end{abstract}

\section{KEY WORDS}

Community, Learning Effectiveness, Interaction, Spirit, Trust, Student Satisfaction

\section{INTRODUCTION}

The past few decades have witnessed increased interest in the concept of community. Etzioni explains that much of this interest is based on the perception that sense of community in this country is weak and that there is a need to get our citizens thinking about working together toward the common good [1]. Some communities work together effectively; others struggle to accomplish their goals. Putnam intensified interest in community with his much-publicized view that too many Americans are "bowling alone," with a resultant decline in social capital or cohesion [2].

In their book Habits of the Heart, Bellah, Madsen, Sullivan, Swidler and Tipton define community as follows:

A community is a group of people who are socially interdependent, who participate together in discussion and decision-making, and who share certain practices that both define the community 
and are nurtured by it. Such a community is not quickly formed. It almost always has a history and so is also a community of memory, defined in part by its past and its memory of the past. [3]

Additionally, McMillan and Chavis offer the following definition for successful community: "a feeling that members have of belonging, a feeling that members matter to one another and to the group, and a shared faith that members' needs will be met through their commitment to be together" [4]. These two definitions taken together identify or imply the most essential elements of community: mutual interdependence among members, connectedness, interactivity, overlapping histories among members, spirit, trust, common expectations, and shared values and beliefs.

Rheingold and Hill identify the need for extensive research in a variety of contexts to fully understand sense of community [5], [6]. They believe that the components of community differ from setting to setting, suggesting that sense of community is setting specific. One such setting is education, the focus of this study. Sergiovanni points out that schools include communities where members are committed to thinking, growing, and inquiring, as well as participants in a $\mathrm{n}$ area where learning is an attitude as well as an activity [7]. He stresses the need for authentic community, a tie binding learners and teachers through shared values and ideals. Bielaczyc and Collins describe such a community as one that embodies a "culture of learning in which everyone is involved in a collective effort of understanding" [8]. Alexander defines this type of community as a group of learners who form a partnership based upon the concern for the welfare of self and others and for the common good [9]. Members of such classroom communities have feelings of belonging and trust. They believe that they matter to one another and to the group, that they have duties and obligations to each other and to the school, and that they possess a shared faith that members' educational needs will be met through their commitment to shared goals. Accordingly, classroom community can be constitutively defined in terms of four components: spirit, trust, interaction, and learning.

The first component, spirit, denotes recognition of membership in a community and the feelings of friendship, cohesion, and bonding that develop among learners as they enjoy one another and look forward to time spent together. Community spirit allows learners to challenge and to nurture each other. Learners need to feel a sense of connectedness, to feel a part of and be included in the group [10]. In contrast, a lack of connectedness may affect the learner's ability to cope. Non-involvement in the classroom community may lead to feelings of loneliness, low self-esteem, isolation, and low motivation to learn, which in turn can lead to low achievement and dropouts.

Trust, the second component, is the feeling that the community can be trusted and feedback will be timely and constructive. Trust represents a willingness to rely on other members of the community in whom one has confidence [11]. Trust consists of two dimensions: credibility and benevolence [12]. The first dimension, credibility, is an expectation that the word or written statements of other learners in the community can be relied on. The second dimension, benevolence, is the extent to which learners are genuinely interested in the welfare of other members of the community and are motivated to assist others in their learning. With trust comes the likelihood of candor-that members will feel safe and expose gaps in their learning and feel that other members of the community will respond in supportive ways. Preece explains, "when there is trust among people, relationships flourish; without it, they wither" [13].

In his classic study of communities and social change in America, Bender views communities as social networks, a concept useful for the study of classroom community in a distance education environment because this concept emphasizes the interactions that create communities [14]. Accordingly, interaction is the third component of classroom community. Interaction is either task-driven or socio-emotional in 
origin [15]. Task-driven interaction is directed toward the completion of assigned tasks while socioemotional-driven interaction is directed toward relationships among learners. Task-driven interaction is under the direct control of the instructor and often takes the form of responses to instructor-generated discussion topics and peer assessments. Peer assessment consists of student assessment of other students, including evaluations of the comments made by other students. Instructors must be able to distinguish between peer assessments that promote community and those that do not. Factors such as student knowledge and personality, communication patterns, reluctance to criticize, fear of criticism and retaliation, unwillingness to give honest feedback, and the difficulty learners may experience in identifying relevant grounds for criticism of each others' work may negatively affect sense of community by reducing feelings of safety and trust among learners.

In contrast, socio-emotional-driven interaction also relies on the instructor to create a discussion environment that promotes such interaction but the interaction itself is largely self-generated. Socializing can take on many characteristics, from exchanging empathetic messages to self-disclosure [16], [17]. According to Cutler, "the more one discloses personal information, the more others will reciprocate, and the more individuals know about each other, the more likely they are to establish trust, seek support, and thus find satisfaction" [18]. Ideally, then, increased disclosure of personal information strengthens classroom community. However, divulging certain types of personal information can be risky behavior, such as identifying addresses, phone numbers, and social security numbers in any online environment, especially by minors. The best type of personal information to disclose is information that helps make connections with others, such as having the same hometown, taking a similar vacation, or attending the same school or church.

Interaction among learners is also an important element of the learning process. Learning, the fourth and final component of classroom community reflects the commitment to a common educational purpose and epitomizes learner attitudes concerning the quality of learning. Situated learning maintains that learning and cognition must take account of social interaction and work [19]. A unifying concept emerging from situated learning research is "communities of practice," the concept that learning is constituted through the sharing of purposeful, patterned activity [20]. This concept stresses practice and community equally. Learning is considered "an integral and inseparable aspect of social practice" within the classroom community [20]. Rather than merely adding to the student's knowledge, learning involves a "process of transformation of participation itself," which occurs as a function of all active members of the classroom community "transforming roles and understanding in the activities in which they participate" [21]. This type of learning leads to deeper understanding of content and processes for the community members [15]. Accordingly, Doll finds new meaning in John Dewey's emphasis on community: "More than being merely a pleasant frame in which to work or in keeping with our democratic beliefs, community, with its sense of both cooperation and critical judgment, may be essential to meaningful, deep learning" [22]. Learning thus represents the common purpose of the community and members of the community grow to feel that their educational needs are being satisfied through active participation in the community.

The move of many schools, particularly post-secondary schools, toward increased use of technology to deliver courses and programs at a distance has raised the question of how best to foster community among learners who are physically separated from each other and from the school [23]. Such physical separation gives rise to feelings of disconnectedness [24], promotes feelings of isolation and lack of personal attention, and inhibits the development of interpersonal relations [25], [26]. Coleman and Hoffer argue that students with poor interpersonal relations are more likely to experience academic failure [27]. These findings suggest that a strong sense of classroom community could have a positive influence on student academic performance. 
Educators who perceive the value of community in the learning process must conceptualize how sense of community can be nurtured in these distant environments. McIsaac and Gunawardena define distant education as structured learning in which the student and instructor are separated by time and place [28]. Proponents of asynchronous learning networks (ALNs) identify two-way communications as the vital characteristic of this form of distance education [29]. Consequently the methods used to deliver courses at a distance have moved away from the classic correspondence model to models that emphasize more rapid communications and interactivity, such as the synchronous model, which uses video and/or audio teleconferencing, and the ALN model, which is popular in delivering post-secondary courses. Mayadas describes the ALN model as a telelearning infrastructure in which learners access resources and interact asynchronously (i.e., not at the same time) [30]. ALNs use computer and communications technologies that allow learners to work with remote learning resources. Thus learners are physically separated but communicate with each other through the use of commercially available software, such as the Blackboard.com ${ }^{\mathrm{SM}}$ e-learning system, without the requirement to be online at the same time. The ALN model is the one examined in this present study.

"The ALN model, in its essence, is a model that facilitates connections between people" [30]. Thus the ALN model also facilitates community, since the essence of community is making connections between people. Bates supports this view and claims that one of the major contributions of two-way technologies is allowing interactions among learners as well as between learners and instructors [31]. Strong feelings of community increase the flow of information among all learners [32], [33], [34]. Learners benefit from community membership by experiencing a greater sense of well-being [35].

Moore emphasizes the importance of interaction to learning in distance education, but observed that the term interaction itself "carries so many meanings as to be useless unless specific sub-meanings can be identified and agreed upon" [36]. Accordingly, he identified three types of interactions: learner-content, learner-instructor, and learner-learner [37]. Moore describes learner-content interaction as the process of intellectually interacting with content for the purpose of acquiring knowledge and understanding, much like the classic correspondence model of distance education and self-paced programmed instruction, which emphasize learner independence and self-motivation for learning. By purposefully using content resources to construct answers to their own questions and achieve their own learning goals, students move beyond "knowledge reproduction" to "knowledge building" [38].

Learner-instructor interaction takes the form of intellectual discussion or stimulating exchanges of ideas [39]. Facilitating productive interactions is probably the most important responsibility of the online instructor. Finally, learner-learner interaction is the sharing of learners' experiences and understandings with each other. Bull, Kimball, and Stansberry found that more effective learning occurs when interactions are not limited to learner-instructor communications but also include communications between learners [40]. Learner-learner interactions have the potential to strengthen or weaken sense of community. Interactions build community when learners trust each other and view other learners as colleagues or collaborators. Conversely, interactions can weaken community when learners view each other as competitors or critics.

Moore reinforced the importance of interaction when he theorized in 1972 that distance education is characterized by dialogue (or, the amount of control exercised by the learner) and structure (or, the amount of control exercised by the instructor) [36]. Additional structure tends to increase distance (decrease community), and more dialogue tends to decrease distance (increase community). Comeaux endorses this view and reported that interaction and collaborative involvement lessened the psychological distance for students at remote learning sites [41]. Vrasidas and McIsaac concluded the need for educators to structure for dialogue because of the need to include learner-learner interactions [39]. Kozma also 
foresaw the need for less structure and more dialogue when he visualized learners actively collaborating with the medium to construct knowledge as opposed to instruction being delivered by the medium [42]. However, there is the danger of overload based on the sheer quantity of interaction that may be required of learners. Kerr and Hiltz note that "intensive interaction with a large number of communication partners results in the mushrooming of the absolute amount of information and the number of simultaneous discussions, conferences, and other activities well beyond normal coping abilities" [43], [44]. Interaction overload can weaken connections between learners thereby reducing feelings of community.

The professional literature also suggests that online instructors need to manifest immediate behaviors when providing feedback to distant learners. Butland and Beebe find evidence that instructor immediacy, such as immediate verbal and nonverbal communications, including timely feedback and use of emoting in text (such as using a word or phrase enclosed in angle-brackets to express emotion, e.g., <sigh>, $<$ grin $>$ ), promote increased learning [45]. Frymier investigates the interaction of students' motivation to study and instructors' verbal and nonverbal immediacy in a traditional face-to-face learning environment [46]. Her research finds that students beginning a course with either low or moderate motivation to study have increased motivation to study after being exposed to a highly immediate instructor, while students with a high level of motivation are unaffected by their instructors' immediacy behaviors.

Research regarding the learning effectiveness of various media for delivering instruction at a distance provides substantial evidence that the medium is rarely the determining factor in learning effectiveness [47]. It is course design and pedagogy that matter the most. However, some types of media used to deliver distance education courses do not lend themselves to the immediate instructor behaviors that are routine in face-to-face learning environments. For example, nonverbal communication can be difficult in an ALN environment and feedback can be delayed based on differing learner and instructor attitudes and behaviors regarding the frequency of course access and perceptions of the need for formal feedback. Thus course design and pedagogy must compensate for media limitations. Accordingly, the present study assumes the educational practicality of the ALN model and the view that course outcomes are primarily functions of course design and pedagogy. Hiltz supports the view that interaction is an important aspect of online pedagogy but points out that "the current 'state of the art' of systems plus pedagogy seems to lead to less feeling of community [in ALN courses] than is typically obtained in face-to-face small group interaction. How to build and sustain online learning communities is thus a prime area where researchers on ALN ought to be focusing their efforts" [44].

In summary, research evidence suggests sense of community is related to interactivity, sense of wellbeing, quality of the learning experience, and effective learning. The move of many post-secondary schools toward increased use of distance education has raised the question of how best to foster community among learners who are physically separated from each other. Some researchers believe that the question of how to build and sustain online learning communities is a prime area where researchers of ALN ought to focus their efforts. Accordingly, this study was designed to answer the following research question: how does sense of community differ between students enrolled in traditional face-to-face and ALN courses? The ultimate goal of this type of research is to identify best practices for promoting community in asynchronously delivered distance education courses.

\section{METHODOLOGY}

\section{A. Subjects}

The experimentally accessible population consists of 413 adult learners who were enrolled in 14 undergraduate and graduate courses in education, government, organizational leadership, or science 
taught at two urban universities, one public and one private. For the purpose of this research an adult learner is defined as a university student over 18 years of age. A total of 326 students volunteered to be subjects in this study (78.93\% volunteer rate), of whom 52 were enrolled in seven Blackboard.com ${ }^{\mathrm{SM}}$ courses $(65.82 \%$ volunteer rate) and 274 were enrolled in seven traditional face-to-face courses $(82.04 \%$ volunteer rate). The sample consisted of 114 males (34.97\%) and 212 females $(65.03 \%)$ of whom 235 were white $(72.09 \%), 58$ were African-American (17.79\%), and 33 were members of other races $(10.12 \%)$. A total of 245 subjects $(75.15 \%)$ were in the youngest category (18 to 25 years of age). The Blackboard.com ${ }^{\mathrm{SM}}$ group consisted of 31 males $(59.62 \%)$ and 21 females $(40.38 \%)$, of whom 42 were White $(80.77 \%), 6$ were African-American (11.54\%), and 4 were members of other races $(7.69 \%)$. The traditional group was comprised of 82 males (29.93\%) and 192 females $(70.07 \%)$, of whom 193 were White (70.44\%), 52 were African-American (18.98\%), and 29 were members of other races (10.58\%). The traditional group was somewhat younger $(76.64 \%$ were 18 to 25 years of age) than the Blackboard.com ${ }^{\mathrm{SM}}$ group $(67.31 \%$ were 18 to 25 years of age).

\section{B. Treatments}

Classes examined by this study were either presented in a traditional face-to-face learning environment or in an ALN course using the Blackboard.com ${ }^{\mathrm{SM}}$ e-learning system [46]. This system consists of an integrated set of application tools that are accessible to students via the Internet. These tools fall into four major categories: (a) productivity tools such as calendars, address books, and information services; (b) communication and collaboration tools, the most important of which are discussion boards, e-mail, and group areas; (c) assessment tools such as computer assisted testing and an online gradebook; and (d) content management tools that allow the online instructor to present rich content online, including hypermedia.

The duration of all courses was one semester (16 weeks). The traditional and Blackboard.com ${ }^{\mathrm{SM}}$ courses were presented as designed by their respective instructors without regard for this study. All instructors were full-time faculty. Furthermore, all faculty were experienced (one year or more) in teaching, in either traditional classrooms or online using the Blackboard.com ${ }^{\mathrm{SM}}$ system. The size of all courses was under 35 students with the exception of two traditional courses that had enrollments of 102 and 105 students respectively. Course design and methods were uncontrolled for the 14 instructors who were randomly selected from a pool of instructors and who subsequently volunteered to participate in this study. Seven of the selected instructors taught traditional face-to-face courses and seven taught ALN-based courses.

\section{Instrumentation}

Data for the study were gathered from: (a) the Sense of Classroom Community Index (SCCI), (b) messages posted by subjects to the Blackboard.com ${ }^{\mathrm{SM}}$ course discussion boards, and (c) overall course statistical data routinely tallied and retained by the Blackboard.com ${ }^{\mathrm{SM}}$ e-learning system [48]. A free copy of the SCCI in Adobe ${ }^{\circledR}$ Acrobat ${ }^{\circledR}$ format can be obtained by contacting the author at alfrrov@regent.edu.

The SCCI was used to measure sense of classroom community. It consists of a self-report questionnaire of 40 items, ten items each for the subscales of spirit, trust, interaction, and learning. Sample items for each subscale are: (a) spirit - "I feel connected to others" and "I feel isolated in this course," (b) trust - "I feel safe in this course" and "I feel uncertain about others in this course," (c) interaction- "I feel that I am encouraged to ask questions" and "I feel that discussions are one-way," and (d) learning- "I feel that this course provides valuable skills" and "I feel that this course does not meet my educational needs." Following each item is a five-point Likert scale of potential responses: "Strongly agree, Agree, Neutral, Disagree, and Strongly disagree." The subjects check the place on the scale that best reflects their feelings 
about the item. One computes scores by adding points assigned to each of the 40 five-point items. These items are reverse-scored where appropriate to ensure the most favorable choice is always assigned a value of four and the least favorable choice is assigned a value of zero. Therefore, the total possible scores range from zero to 160, with higher scores reflecting a stronger sense of classroom community. Similarly, scores for each of the four SCCI subscales of spirit, trust, interaction, and learning range from zero to 40 .

The SCCI possesses high face validity. An examination of items reveals that on face value they appear to measure what is needed to assess sense of classroom community. Additionally, the procedures used to develop the SCCI provide high confidence that the instrument also possesses high content and construct validities. Considerable effort was expended to ensure that: (a) the concept of classroom community was based on the general concept of community as contained in the professional literature, (b) classroom community is seen as a type of community that is applied to an educational setting, and (c) the SCCI captures all four components of classroom community [3], [4], [7], [9], [14]. Additionally, the SCCI was presented to a panel of experts consisting of three university professors who taught courses in educational psychology. Each expert independently rated the relevance of each SCCI item to sense of community in a classroom environment using a 4-point Likert scale consisting of "Totally not relevant, Barely relevant, Reasonably relevant, and Totally relevant." The potential score for each item ranges from zero (Totally not relevant) to 4 (Totally relevant). The mean score for each SCCI item as evaluated by the expert panel ranged from a low of 3.33 to a high of 4.00 .

Cronbach's coefficient alpha was applied to SCCI scores obtained from a sample of 511 undergraduate and graduate university students enrolled in a variety of traditional and distance education courses to determine instrument reliability. Resultant coefficients of internal consistency were .96 for the overall SCCI score, .90 for the spirit subscale, .84 for the trust subscale, .84 for the interaction subscale, and .88 for the learning subscale. These findings provide evidence that classroom community and each of its components have high to very high internal consistencies and that the SCCI can reliably measure classroom community in a group of post-secondary students. The norm for all students in this sample was $\underline{\mathrm{M}}=112.49, \underline{\mathrm{SD}}=21.21$, which reflects sense of community during the final week of the course in which students were enrolled. The female norm $(\underline{\mathrm{N}}=366)$ was $\underline{\mathrm{M}}=113.48, \underline{\mathrm{SD}}=20.29$, and the male norm $(\underline{\mathrm{N}}=$ 145) was $\underline{\mathrm{M}}=110.43, \underline{\mathrm{SD}}=23.36$.

\section{Procedure}

For traditional courses, the SCCI was administered to subjects at the beginning of the final class period of the course. The course instructor encouraged students to participate in the study and introduced the researcher who read the SCCI directions verbatim from the SCCI manual, allowed sufficient time for all volunteers to complete the questionnaire, and collected the SCCI. The researcher then manually scored all completed questionnaires. For Blackboard.com ${ }^{\mathrm{SM}}$ courses, the SCCI with directions was placed online during the penultimate week of the semester. The course instructor and researcher e-mailed all students and encouraged them to complete the questionnaire. During the middle of the week students were again individually contacted by e-mail and encouraged to complete the questionnaire if they had not already done so. During the final week of the course the completed online questionnaires were printed and manually scored by the researcher.

\section{E. Design and Data Analysis}

The causal-comparative method was used for this research. Subjects enrolled themselves in either traditional or Blackboard.com ${ }^{\mathrm{SM}}$ courses based on their interests and needs. There was no attempt by this study to assign subjects to specific types of courses. Therefore it is possible that subjects in traditional and 
Blackboard.com ${ }^{\mathrm{SM}}$ courses differ from each other in ways that are not known and which could confound the results of this study.

Descriptive statistics were calculated for classroom community, as operationalized by the SCCI, and for the number of messages posted by subjects to the Blackboard.com ${ }^{\mathrm{SM}}$ discussion boards. Independent ttests and a one-way analysis of variance (ANOVA) were conducted to determine if differences in classroom community existed between the traditional and distance education groups and between all 14 courses. A Pearson product-moment correlation coefficient was also computed for classroom community and the number of messages posted. Finally, a two-group descriptive discriminant analysis was conducted to determine how students enrolled in traditional and Blackboard.com ${ }^{\text {SM }}$ courses differ based upon their responses to the SCCI items. The independent (predictor) variables were the 40 items contained in the SCCI and the dependent variable was group membership (traditional or Blackboard.com ${ }^{\mathrm{SM}}$ ), a nominal scale variable. A stepwise procedure was used because there were no reasons for assigning some predictors higher priority than others.

\section{RESULTS}

Table 1. Classroom Community Statistics for Traditional and Blackboard.com ${ }^{\text {SM }}$ Courses

\begin{tabular}{|c|c|c|c|c|c|}
\hline & Class Size & $\underline{N}$ & $\underline{\mathrm{M}}$ & $\underline{\mathrm{SD}}$ & $\underline{\text { Tukey's HSD }}$ \\
\hline \multicolumn{6}{|c|}{ Traditional Courses } \\
\hline $\mathrm{T} 1$ & 13 & 8 & 137.00 & 17.87 & $\mathrm{~T} 2 *, \mathrm{~T} 3 *, \mathrm{~T} 5 *, \mathrm{~T} 6 *$ \\
\hline $\mathrm{T} 2$ & 30 & 24 & 104.50 & 23.03 & $\mathrm{~T} 1 *, \mathrm{~T} 7 *$ \\
\hline $\mathrm{T} 3$ & 20 & 17 & 108.65 & 19.60 & $\mathrm{~T} 3 *$ \\
\hline $\mathrm{T} 4$ & 34 & 24 & 114.25 & 14.63 & \\
\hline $\mathrm{T} 5$ & 102 & 84 & 107.73 & 18.39 & $\mathrm{~T} 1 *, \mathrm{~T} 7 * *$ \\
\hline T6 & 105 & 90 & 108.27 & 19.16 & $\mathrm{~T} 1 *, \mathrm{~T} 7 * *$ \\
\hline T7 & 30 & 27 & 127.19 & 16.52 & $\mathrm{~T} 2 *, \mathrm{~T} 5 * *, \mathrm{~T} 6 * *$ \\
\hline \multicolumn{6}{|c|}{ Blackboard.com ${ }^{\mathrm{SM}}$ Courses } \\
\hline $\mathrm{Bb} 1$ & 8 & 8 & 125.50 & 29.15 & \\
\hline $\mathrm{Bb} 2$ & 13 & 7 & 110.29 & 17.18 & \\
\hline Bb3 & 16 & 7 & 109.00 & 34.71 & \\
\hline $\mathrm{Bb} 4$ & 17 & 8 & 130.00 & 15.75 & \\
\hline Bb5 & 13 & 11 & 117.18 & 12.65 & \\
\hline Bb6 & 5 & 4 & 104.20 & 26.71 & \\
\hline $\mathrm{Bb} 7$ & 7 & 7 & 106.00 & 24.16 & \\
\hline
\end{tabular}

Notes: $\underline{\mathrm{N}}=326 .{ }^{*} \mathrm{p}<.05 . * * \mathrm{p}<.001$

Table 1 shows the descriptive statistics for classroom community by course. Overall, subjects enrolled in Blackboard.com ${ }^{\mathrm{SM}}$ courses manifested somewhat higher levels of classroom community and variability $(\underline{\mathrm{M}}=115.87, \underline{\mathrm{SD}}=23.53)$ than subjects enrolled in traditional courses $(\underline{\mathrm{M}}=111.02, \underline{\mathrm{SD}}=19.96)$, but 
these differences were not significant, $\underline{\mathrm{t}}(324)=1.56, \underline{\mathrm{p}}=.12$. However, when one removes the two Blackboard.com ${ }^{\mathrm{SM}}$ courses with the lowest community $(\mathrm{Bb} 6$ and $\mathrm{Bb} 7)$ from the analysis, the resultant increased Blackboard.com ${ }^{\mathrm{SM}}$ mean $(\underline{\mathrm{M}}=118.73, \underline{\mathrm{SD}}=22.84)$ is significantly higher than the mean for the traditional courses, $\underline{\mathrm{t}}(313)=2.26, \underline{\mathrm{p}}=.02$. Figure 1 shows the contributions made by the spirit, trust, interaction, and learning components of classroom community to total sense of community score by course.

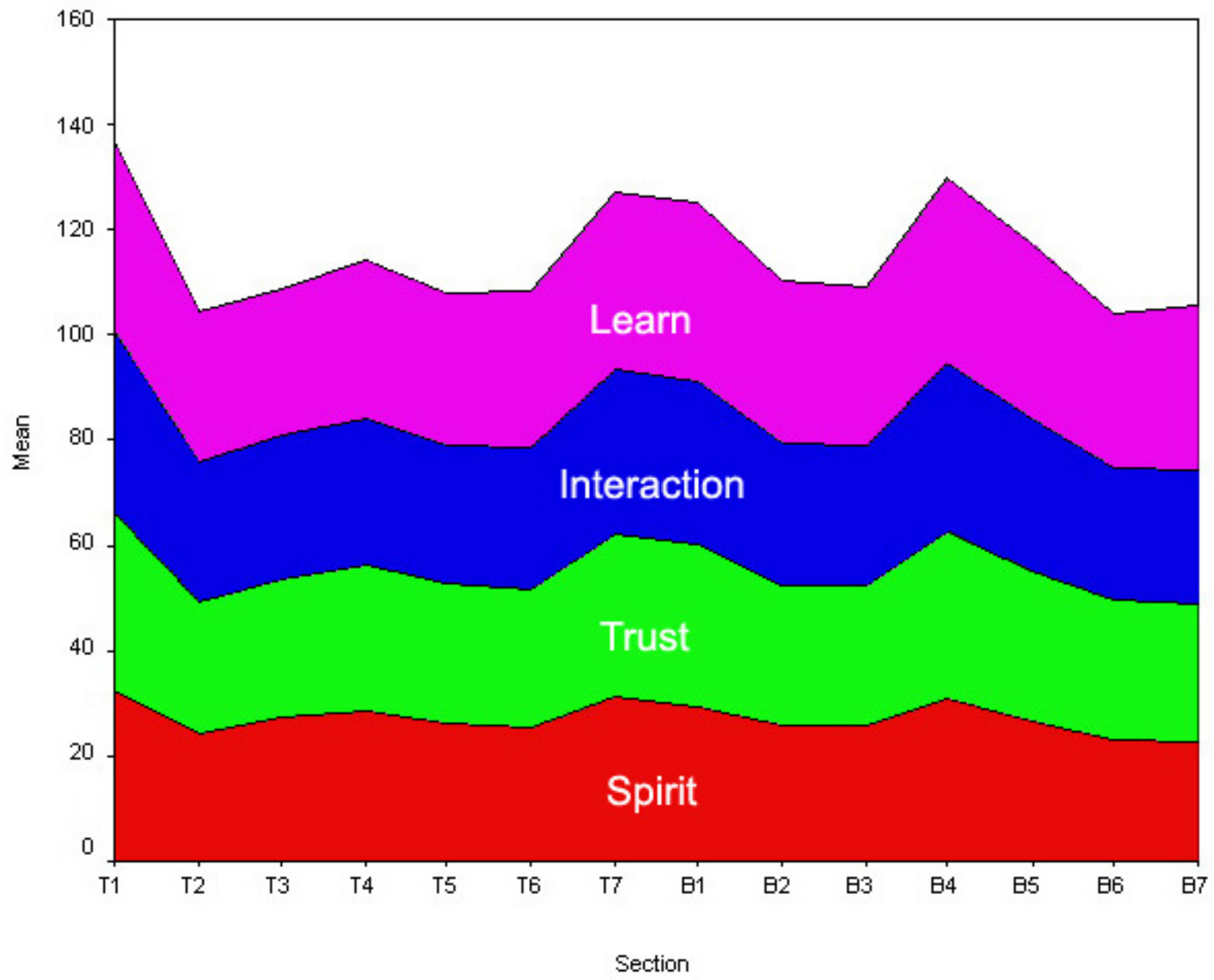

Figure 1. Stacked area chart showing total classroom community by course and the contributions made by the spirit, trust, interaction, and learning components (by area from bottom to top). Courses labeled with a T\# are traditional courses, with $\mathrm{T} 5$ and $\mathrm{T} 6$ class size $>100$. Bb\# courses are Blackboard.com ${ }^{\mathrm{SM}}$ courses.

A one-way ANOVA was conducted to evaluate the differences between courses. The independent variable was class group with 14 levels, one for each of the seven traditional and seven Blackboard.com ${ }^{\text {SM }}$ classes. The dependent variable was classroom community as measured by the SCCI. The ANOVA produced significant results, $\underline{F}(13,312)=4.21, \underline{p}<.001$. Since the assumption of homogeneity of variances was tenable, post hoc multiple comparison tests were conducted using Tukey's Honestly Significant Difference (HSD) procedure. The results of these tests are also reported in Table 1. None of the Blackboard.com ${ }^{\mathrm{SM}}$ course means were significantly different from each other or from any of the traditional course means. 
Subjects in the Blackboard.com ${ }^{\mathrm{SM}}$ group posted a minimum of one message and a maximum of 115 messages $(\underline{\mathrm{M}}=40.98, \underline{\mathrm{SD}}=25.94)$ to the Blackboard.com ${ }^{\mathrm{SM}}$ discussion boards. A moderate positive relationship was found between classroom community and number of messages posted by subjects, $\underline{r}=$ $.42, \mathrm{p}=.003$, using the Pearson product-moment correlation procedure. The coefficient of determination was .18. A comparison of the number of messages posted by subjects in the three high-community Blackboard.com ${ }^{\mathrm{SM}}$ courses $(\underline{\mathrm{M}}=52.90, \underline{\mathrm{SD}}=24.15$ ) (see Table 1 and Figure 1, courses $\mathrm{Bb} 1, \mathrm{Bb} 4$, and $\mathrm{Bb5}$ ) to the number of messages posted by students in the remaining four low-community Blackboard.com ${ }^{\mathrm{SM}}$ courses $(\underline{\mathrm{M}}=30.77, \underline{\mathrm{SD}}=23.16)$ reveals a highly significant difference, $\underline{\mathrm{t}}(63)=3.77$, $\mathrm{p}<.001$. The Blackboard.com ${ }^{\mathrm{SM}}$ course with the lowest classroom community (see Table 1 and Figure 1, course Bb6; $\underline{M}=104.20, \underline{\mathrm{SD}}=26.71$ ) also had the lowest number of messages posted to the course discussion boards. Only five messages were posted during the entire course.

The two groups of Blackboard.com ${ }^{\mathrm{SM}}$ and traditional course subjects were compared with regard to the 40 SCCI items using a two-group stepwise discriminant analysis. Discriminant analysis assumptions requiring group membership to be mutually exclusive and collectively exhaustive were tenable because no subject belonged to more than one group and all subjects were members of one of the two groups. Evaluation of assumptions of linearity, normality, and multicollinearity revealed no threats to multivariate analysis. The maximum entry criterion for $\underline{\mathrm{F}}$ used in the discriminant analysis was $\underline{p}=.05$ and the minimal removal criterion for $\underline{F}$ was $\underline{p}=.10$. The centroid (mean vector) for the traditional group was -.29 and that for the Blackboard.com ${ }^{\mathrm{SM}}$ group was 1.51. The canonical correlation, which measures the strength of relationship between the discriminant scores and the groups, was a moderate .55 . The test of equality of group centroids is typically measured by the Wilks lambda statistic. Accordingly, the discriminant analysis procedure, which terminated at step 10 , resulted in Wilks' lambda $=.70$, which indicates that $70 \%$ of the variance between groups cannot be explained by group differences. This is equivalent to $\chi^{2}(10)=114.83, \underline{p}<.001$. Consequently there is evidence to reject the null hypothesis that the means of all predictors across both groups are equal.

Table 2. Means and Standard Deviations on SCCI Items for Blackboard and Traditional Groups, with Corresponding Difference Scores and Standardized Discriminant Function Coefficients

\begin{tabular}{|c|c|c|c|c|c|c|}
\hline \multirow[b]{2}{*}{ SCCI Item } & \multicolumn{2}{|c|}{ Blackboard } & \multicolumn{2}{|c|}{ Traditional } & \multirow{2}{*}{$\begin{array}{l}\text { Difference } \\
\text { score } \\
(\underline{\mathrm{df}}=151)\end{array}$} & \multirow{2}{*}{$\begin{array}{l}\text { Discriminant } \\
\text { function } \\
\text { coefficients }\end{array}$} \\
\hline & $\underline{\mathrm{M}}$ & $\underline{\mathrm{SD}}$ & $\underline{\mathrm{M}}$ & $\underline{\mathrm{SD}}$ & & \\
\hline Similarity of learner needs & 2.65 & .65 & 2.91 & .70 & $.26^{*}$ & -.60 \\
\hline Recognition & 2.88 & .73 & 2.41 & .87 & $.47 * *$ & .57 \\
\hline Importance of learning & 3.50 & .58 & 3.07 & .70 & $.43 * *$ & .53 \\
\hline Connectedness & 2.35 & .99 & 2.58 & .92 & .23 & -.45 \\
\hline Friendship & 2.52 & .98 & 2.79 & .85 & $.27 *$ & -.44 \\
\hline Thinking critically & 3.29 & .67 & 2.84 & .83 & $.45^{* *}$ & .42 \\
\hline Safety & 2.69 & .73 & 2.42 & .83 & $.27 *$ & .36 \\
\hline Acceptance & 3.02 & .64 & 2.66 & .69 & $.36^{* *}$ & .35 \\
\hline Group identity & 2.42 & .91 & 2.63 & .94 & .21 & -.31 \\
\hline Absence of confusion & 2.83 & 1.00 & 3.01 & .85 & .18 & -.27 \\
\hline
\end{tabular}

Note: $* \underline{p}<.05 . * \underline{p}<.01$. 
Table 2 reports the means and standard deviations of the ten SCCI items by group that produced a significant discriminant function, the results of univariate analyses using independent t-tests to test differences by SCCI item between the two groups, and the standardized discriminant function coefficients for the ten SCCI items that contributed to the discriminant analysis solution. These coefficients show the relative contribution of each variable to the differentiation of the two groups of subjects. ALN courses scored higher on five items while traditional courses scored higher on the remaining five items. The items in which the ALN courses scored higher are learner feelings of: (a) recognition, (b) the importance of learning in the course, (c) thinking critically in the course, (d) safety, and (e) acceptance. The two items that address feelings regarding the importance of learning and critical thinking contributed to the learning subscale of community whereas the two items dealing with recognition and acceptance contributed to the spirit subscale. Feelings of safety are related to the trust subscale. The items in which the traditional courses scored higher are learner feelings of: (a) similarity of learner needs, (b) connectedness, (c) friendship, (d) group identity, and (e) absence of confusion. All items contributed to the spirit subscale with the exception of absence of confusion in course discussions, which contributed to the interaction subscale.

Classification results showed that $83.4 \%$ of original grouped cases were correctly classified by the canonical discriminant function. Out of 274 subjects in traditional courses, group membership was correctly predicted for 230 subjects, and out of 52 subjects in Blackboard.com ${ }^{\text {SM }}$ courses, group membership was correctly predicted for 42 subjects. In calculating the correctly classified and misclassified subjects, the correctly classified subjects are the same ones used to estimate the coefficients shown in Table 2. This procedure produces an optimistic estimate of the success of the classification. Consequently a leave-one-out cross-validation procedure was used to help eliminate this optimistic bias and check the stability of the classification. Using this procedure each subject is classified into one of the two groups according to the discriminant function computed from all the data except the subject being classified. The proportion of misclassified subjects after removing the effect of each subject one at a time is the leave-one-out estimate of misclassification. For the dataset used in this analysis the optimistic correct classification was $83.4 \%$ as reported above. The leave-one-out correct classification was $80.7 \%$, resulting in a modest $2.7 \%$ shrinkage.

\section{DISCUSSION}

Community is about individuals who interact and become connected with each other as members of formal and informal organizations. The professional literature suggests that the ALN model of distance education can promote connections between people in a virtual classroom environment. Interactions in such environments, and the sense of community such interactions can generate, have the potential to be equal to that sustained in traditional classrooms because of the fact that discussion boards, the heart of ALN learner-learner and learner-instructor interactivity, can support discussions that are both task-driven and socio-emotional-driven in origin. It is therefore reasonable to hypothesize that ALN courses can build and sustain classroom community at levels similar to levels experienced in traditional face-to-face courses. However, the research literature suggests distance education courses are often characterized by disconnectedness and feelings of isolation, which suggest lower levels of community. Accordingly, this study addressed the following research question: How does sense of community differ between students enrolled in traditional face-to-face and ALN courses?

The methods used by both traditional and ALN instructors were not controlled in the present study in order to determine if a group of 14 university professors, each designing and delivering courses without researcher influence in their respective course delivery medium, resulted in less feelings of community 
among students in the distance education courses than in the traditional courses delivered in a live face-toface classroom environment. The results of this study do not support the view of some researchers (e.g., Besser and Donahue, 1996; Hiltz, 1998; Kerka, 1996; Twigg, 1997) that the current state of the art of ALN e-learning systems plus pedagogy leads to less feelings of community than is typically obtained in face-to-face small group interaction [24], [25], [26], [44]. On the contrary, the results of this study provide evidence that there is no significant difference in overall sense of classroom community, as operationalized by the SCCI, between ALN courses and traditional courses, provided the courses are designed and taught by experienced instructors. Specifically, there are no significant differences in community between the seven Blackboard.com ${ }^{\mathrm{SM}}$ courses and the seven traditional courses examined by this study. Additionally, as a group the five Blackboard.com ${ }^{\mathrm{SM}}$ courses with the highest community means have a significantly higher sense of community than the group of seven traditional courses. This finding suggests that the feelings of disconnectedness and isolation that have been reported in many postsecondary e-learning courses tend to be related to individual course design and/or pedagogy rather than to the e-learning system itself. The data also suggests that experienced online instructors can build and sustain levels of community that are at least equal to those experienced in traditional classrooms.

Of additional interest is the finding that variability of community in the distance education courses was higher than in traditional courses $(\underline{\mathrm{SD}}=23.53$ versus $\underline{\mathrm{SD}}=19.98)$. This finding suggests community is more sensitive to ALN course design and pedagogy than to traditional course design and pedagogy. A rationale to support this finding is that the discussion environment in a traditional course is more natural than in an ALN course, where interaction is via text-based discussion boards that the instructor must create and facilitate. In the first instance minimal instructor and learner effort is required for interactions to take place, while the e-learning environment requires more attention and effort on the part of both the instructor and learners.

The moderate positive relationship between classroom community and number of e-learning system messages posted by subjects in this study provides evidence to confirm the notion that interactivity is an important component of community building. These results lend support to Moore's view that structure tends to increase distance (decrease community), and more dialogue tends to decrease distance (increase community) [37]. The instructors of the four ALN courses with the lowest levels of interactivity placed more emphasis on structure than on dialogue when they designed and facilitated their courses. In particular, course Bb6 only contained a total of five messages in its discussion boards. Although the amount of e-mail traffic among the community of learners in this course is not known, it appears as if this course was designed along the lines of the classic correspondence course with strong emphasis on structure. Not surprisingly, these four ALN courses also possessed the weakest sense of classroom community, with course Bb6 generating the least amount of community of all 14 courses sampled by this study. Kozma would probably characterize these four courses as mostly delivering instruction rather than designing instruction so learners actively collaborate with the medium and each other to construct knowledge [42].

However, levels of learner-learner and learner-instructor interactivity represent only one aspect of community since only $18 \%$ of the variance of classroom community can be explained by changes in the number of messages posted by students. Other variables that may be related to classroom community and that could account for at least a portion of the unexplained variance are: (a) instructor immediacy, (b) dialogue or the amount of control exerted by the learner, (c) learner-content interactions, (d) and the content of learner-learner and learner-instructor interactions. This last variable is highly important as interactions that build community provide constructive comments and reflect trust, solidarity, and collegiality. Conversely, interactions that are critical or show tension or antagonism weaken sense of community. 
The discriminant analysis identifies factors that should be addressed by online instructors if community is to be nurtured and sustained. The ten SCCI items that resulted in a significant discriminant function represent the most important variables for discriminating group membership between Blackboard.com ${ }^{\mathrm{SM}}$ and traditional courses in this study. This analysis showed that $30 \%$ of the variance in classroom community between traditional and Blackboard.com ${ }^{\text {SM }}$ courses can be explained by variations in these ten SCCI items. The five items in which traditional courses scored higher than ALN courses represent the areas that online instructors need to emphasize in order to increase sense of community. Accordingly, online instructors need to increase learner feelings of: (a) similarity of learner needs, (b) connectedness, (c) friendship, and (d) group identity; and they need to reduce feelings of confusion in course discussions. Four of these areas are directly related to improving the spirit component of classroom community; and one, reducing feelings of confusion, is related to improving the interaction component. However, in a larger sense all these areas have the potential to affect other community components. For example, reducing feelings of confusion in course discussions should improve learning as well as interaction. If these areas can be improved it is possible that sense of community in ALN courses will surpass that of traditional courses given the current state of the art of e-learning system software.

Creating an online environment that promotes socio-emotional-driven interaction, such as exchanging empathetic messages, encouraging self-disclosure, and discussing the backgrounds and interests of learners may help promote feelings of friendship and connections to others and may even promote feelings that other learners have similar needs [16], [17]. Bringing most learners together, at least for an initial get-acquainted and orientation session, may also help build group identity and cohesion. If this is not possible, the online instructor needs to substitute something like early placement of learners into groups for informal discussions and group work. Emphasis on online interactions can help generate a group identity, particularly if the interaction is a component of collaborative work. When group work is absent or infrequent, group identity will likely be difficult to establish and nurture. Learners must feel mutually interdependent. This interdependence can promote an atmosphere of joint responsibility and a sense of personal and group identity, thereby nurturing sense of community.

Special attention is also needed in the design of courses to promote clarity of learner-content, learnerlearner, and learner-instructor interactions. This goal can be facilitated if the online instructor promotes effective communication by posting a complete syllabus at the beginning of the course; setting clear guidelines for posting assignments and for discussions; establishing unambiguous expectations, perhaps using a rubric; providing appropriate scaffolding to assist students that require assistance on all instructional tasks; and giving clear and detailed feedback, especially on the first individual assignment. Additionally, studies of students using computer-mediated communication to accomplish learning tasks have shown that the use of templates or texts to guide interaction produces more effective communication between participants [49], [50].

Of interest are the five SCCI items in which the ALN courses scored higher than the traditional courses, suggesting that the ALN medium is able to address these areas better than a traditional classroom. These areas are learner feelings of: (a) recognition, (b) the importance of learning in the course, (c) thinking critically in the course, (d) safety, and (e) acceptance. Feelings that learners have of thinking more critically in an ALN course may be linked to the reflective type of communications that are characteristic of the ALN medium, characteristics that are not often demanded in lecture-based university courses. As Kaye puts it, computer conferencing systems provide more "reflective and thoughtful analysis and review of earlier contributions" than in traditional courses where an important contribution may be missed forever [51]. Additionally, reflective communication can possibly assist some learners whose communication skills are not as advanced as those of other learners, particularly when a learner's native 
language is not the same as the majority of community members.

Classroom community is likely to remain an important research topic in the field of distance education. Future research should identify the best practices in designing and facilitating online courses, since this study provides evidence that online courses can build and sustain sense of community that is comparable to or superior to that achieved in traditional courses. The development of the proper pedagogy most suited to each medium of distance education is a challenge. If we can learn what aspects foster a strong sense of classroom community - and can learn to increase those aspects-perhaps we can concentrate on forming strong learning communities and rely on the communities to promote a sense of well being, the quality of the learning experience, and effective learning.

The ability to generalize findings beyond the present study is limited because only two universities were sampled and the learner characteristics, course content, and course design and pedagogy used by various instructors in the present study may not be representative of other university settings. Other variables that could also be important in studies of community are instructor communications and writing styles, instructor teaching styles and student learning preferences, course design and content, instructor immediacy, cultural communication patterns, student social strata, levels of student education, levels of thinking reflected in online discussions, and course length. Future research might examine the relationships of these variables to classroom community and identify online course designs and pedagogy that promote and sustain classroom community.

\section{REFERENCES}

1. Etzioni, A. The Spirit of Community: Rights, Responsibility, and the Communitarian Agenda. New York: Crown, 1993.

2. Putnam, R.D. Bowling Alone: America's Declining Social Capital. Journal of Democracy, 6, 6578, January 1995.

3. Bellah, R. N., Madsen, R., Sullivan, W.M. Swidler, A. and Tipton, S.M. Habits of the Heart: Individualism and Commitment in American Life. New York: Harper and Row, 1985.

4. McMillan, D.W. and Chavis, D.M. Sense of Community: A Definition and Theory. Journal of Community Psychology, 14(1), 6-23, 1986.

5. Rheingold, H. The Virtual. New York: Summit, 1991.

6. Hill, J.L. Psychological Sense of Community: Suggestions for Future Research. Journal of Community Psychology, 24(4), 431-438, 1996.

7. Sergiovanni, T.J. Building Community in Schools. New York: Jossey-Bass, 1994.

8. Bielaczyc, K. and Collins, A. Learning Communities in Classrooms: A Reconceptualization of Educational Practices. In C. M. Reigeluth (Ed.) Instructional-Design Theories and Models: A New Paradigm of Instructional Theory, New Jersey: Lawrence Erlbaum, 269-292, 1999.

9. Alexander, G. C. Community: The Cornerstone of Building a Public Philosophy of Cultural Democracy and Democratic Culture. Paper presented at the International Systems Institute, Asilomar Conversation on the Comprehensive Design of Social Systems, Monterey, California, November 1-5, 1997.

10. Gibbs, J. Tribes. Sausalito, CA: Center Source Systems, 1995.

11. Moorman, C., Zaltman, G. and Deshpande. R. Factors Affecting Trust in Market Research Relationships, Journal of Marketing, 57 (January), 81-101, 1993.

12. Doney, P. M. and Cannon, J.P. An Examination of the Nature of Trust in Buyer-Seller Relationships, Journal of Marketing, 61 (April), 35-51, 1997.

13. Preece, J. Online Communities: Designing Usability, Supporting Sociability. New York: Wiley and Sons, 2000. 
14. Bender, T. Community and Social Change in America. New Brunswick, NJ: Rutgers University Press, 1978.

15. Hare, A. P. and Davies, M. F. Social Interaction. In A. P. Hare, H. H. Blumberg, M. F. Davies, and M. V. Kent (Eds.), Small Group Research: A Handbook (pp. 169-193). Norwood, NJ: Ablex, 1994.

16. diSessa, A. and Minstrell, J. Cultivating Conceptual Change with Benchmark Lessons. In Thinking Practices in Mathematics and Science Learning. J. Greeno and S. Goldman, Editors. New Jersey: Lawrence Erlbaum, 155-188, 1998.

17. McMahon, T. A. From Isolation to Interaction? Network-Based Professional Development and Teacher Professional Communication. Paper presented at the annual meeting of the American Educational Research Association, Chicago, IL. (ERIC Document Reproduction Service No. ED 408 257), 1997.

18. Cutler, R. H. Technologies, Relations, and Selves. In Communication and Cyberspace: Social Interaction in an Electronic Environment (pp. 317-333). L. Strate, R. Jacobson, and S. B. Gibson, Editors. Cresskill, NJ: Hampton Press, 1996.

19. Brown, J.S. Collins, A. and Duguid, P. Situated Cognition and the Culture of Learning. Educational Researcher, 18, 32-42, 1989.

20. Lave, J. and Wenger, E. Situated Learning: Legitimate Peripheral Participation. Cambridge: Cambridge University Press, 1991.

21. Rogoff, B. Developing Understanding of the Idea of Communities of Learners. Mind, Culture, and Activity, 1(4), 209-229, 1994.

22. Doll, W.E. A Post-Modern Perspective on Curriculum. New York: Teachers College Press, 1993.

23. Palloff, R. M. and Pratt, K. Building Learning Communities in Cyberspace. San Francisco: Jossey-Bass Publishers, 1999.

24. Kerka, S. Distance Learning, the Internet, and the World Wide Web. ERIC Digest. (ERIC Document Reproduction Service No. ED 395 214), 1996.

25. Besser, H. and Donahue, S. Introduction and Overview: Perspectives on . . . Distance Independent Education, Journal of the American Society for Information Science, 47(11), 801-804, 1996.

26. Twigg, C.A. Is Technology a Silver Bullet? Educom Review (March/April), 28-29, 1997.

27. Coleman, J.S. and Hoffer, T. Public and Private Schools: The Impact of Communities. New York: The Free Press, 1987.

28. McIsaac, M.S. and Gunawardena, C.N. Distance Education. In Handbook of Research for Educational Communications and Technology (pp. 403-437). David Jonassen, Editor. New York: Simon and Shuster Macmillan, 1996.

29. Shale, D. and Garrison, D. R. Education and Communication. In Education at a Distance: From Issues to Practice (pp 23-29). D. R. Garrison and D. Shale, Editors. Malabar, FL: Krieger, 1990.

30. Mayadas, F. Asynchronous Learning Networks: Alfred P. Sloan Foundation's Program in Learning Outside the Classroom. Journal of Asynchronous Learning Networks, 1(1), 1-14, 1994.

31. Bates, A. W. Distance Education. In The International Encyclopedia of Education (2nd ed. pp. 1573-1580). T. Husen and T. N. Postlethwaite, Editors. Oxford: Elsevier Science, 1994.

32. Bruffee, K. A. Collaborative Learning: Higher Education, Interdependence, and the Authority of Knowledge. Baltimore: John Hopkins University Press, 1993.

33. Dede, C. The Evolution of Distance Education: Emerging Technologies and Distributed Learning. American Journal of Distance Education, 10(2), 4-36, 1996.

34. Wellman, B. The Network Community: An Introduction to Networks in the Global Village. In Networks in the Global Village. Wellman, B., Editor. Boulder, CO: Westview Press, 1999.

35. Wellman, B. and Gulia, M. The Network Basis of Social Support: A Network is More than the Sum of its Ties. In Networks in the Global Village (pp. 83-118). B. Wellman, Editor. Boulder, CO: Westview Press, 1999.

36. Moore, M. G. Learner Autonomy: The Second Dimension of Independent Learning. Convergence 5(2), 76-88, 1972. 
37. Moore, M. G. Editorial: Three Types of Interaction. The American Journal of Distance Education, 3(2), 1-7, 1989.

38. Scardamalia, M. and Bereiter, C. Computer Support for Knowledge-Building Communities. In CSCL: Theory and Practice of an Emerging Paradigm (pp. 249-268). T. Koschmann, Editor. Mahweh, NJ: LEA, 1996.

39. Vrasidas, C. and McIsaac, M. S. Factors Influencing Interaction in an Online Course. American Journal of Distance Education, 13(3), 22-36, 1999.

40. Bull, K. S., Kimball, S. L. and Stansberry, S. Developing Interaction in Computer Mediated Learning. (ERIC Document Reproduction Service No. ED 417 902), 1998.

41. Comeaux, P. The Impact of an Interactive Distance Learning Network on Classroom Communication. Communication Education, 44, 355-361, 1995.

42. Kozma, R.B. Learning with Media. Review of Educational Research, 61(2), 179-211, 1991.

43. Kerr, E. B. Computer-Mediated Communication Systems: Status and Evaluation. New York: Academic Press, 1982.

44. Hiltz, S. R. Collaborative Learning in Asynchronous Learning Networks: Building Learning Communities. Invited address at the WEB98 Conference, Orlando, Florida, 1998.

45. Butland, M.J. and Beebe, S.A. A Study of the Application of Implicit Communication Theory to Teacher Immediacy and Student Learning. Paper presented at the Annual Meeting of the International Communication Association, Miami. (ERIC Document Reproduction Service No. ED 346 532), 1992.

46. Frymier, A. B. The Impact of Teacher Immediacy on Students' Motivation Over the Course of a Semester. Paper presented at the Annual Meeting of the Speech Communication Association, Miami Beach, FL. (ERIC Document Reproduction Service No. ED 367 020), 1993.

47. Russell, T.L. No significant difference phenomenon. Raleigh, NC: North Carolina State University, 1999.

48. Rovai, A.P. and Lucking, R.A. Measuring the Sense of Classroom Community. Manuscript submitted for publication, 2000.

49. Tergan, S. O. Multiple Views, Contexts, and Symbol Systems in Learning with Hypertext/Hypermedia: A Critical Review of Research. Educational Technology, 37(4), 5-18, 1997.

50. Tiberghien, A. and De Vries, E. Relating Characteristics of Teaching Situations to Learner Activities. Journal of Computer Assisted Learning, 13(3), 163-174, 1997.

51. Kaye, A.R. Learning Together Apart. In A.R. Kaye (Ed.), Collaborative Learning Through Computer Conferencing (pp. 1-24). London: Springer-Verlag, 1992.

\section{ABOUT THE AUTHOR}

Fred Rovai received his Ph.D. in Academic Leadership and M.S. in Education from Old Dominion University, M.A. in Public Administration from the University of Northern Colorado, and B.S. in Mathematics from San Jose State University. He currently teaches research and statistics courses at Regent University in Virginia Beach, Virginia, in both a traditional classroom and online using the Blackboard.com ${ }^{\mathrm{SM}}$ e-learning system. Previously he was an online instructor for UCLA Extension, teaching courses in the Online Teaching Program. Contact Information: Alfred P. Rovai-Corresponding Author, Regent University School of Education, 1000 Regent University Drive, Virginia Beach, VA 23464-9800; Phone: (757) 226-4861; Fax: (757) 226-4147; E-mail: alfrrov@regent.edu 